\title{
SôBRE A SALGA DA SARDINHA E DA MANJUBA
}

\author{
Masayuki Furuya
}

No Estado de São Paulo, os peixes mais freqüentemente salgados, em escala industrial, são a sardinha verdadeira (Sardinella aurita Rafinesque) e a manjuba (Anchoviella hubbsi Hildebrand). $\mathrm{O}$ procedimento seguido pelas nossas indústrias consiste em salgar a sêco em tanques e deixar que a "cura" se complete na salmoura que se forma naturalmente. Por quanto tempo os peixes devem ser mantidos no tanque é uma questão que só poderia ser esclarecida por experimentação, pois ela depende de diversos fatôres, tais como o tamanho do peixe, o teor de gordura, a temperatura ambiente, a composição química do sal e a sua granulometria, o fato de estar ou não escalado o peixe, a uniformidade com que o mesmo é pôsto em contato com o sal, etc. Sôbre a matéria, Tanikawa $(1949)^{1}$ cita vários trabalhos que dizem respeito a peixes comumente salgados no hemisfério norte. Quanto às nossas espécies, acima referidas, dispomos apenas de informações díspares dos técnicos das indústrias, não fundamentadas por determinações quantitativas. No presente trabalho procuramos, pois, verificar a rapidez com que se processa realmente a "cura" das duas espécies citadas, através da dosagem do cloreto.

\section{PARTE EXPERIMENTAL}

1) Material ensaiado - Os peixes foram adquiridos nos lugares onde costumam ser entregues aos agentes das indústrias, ou sejam, dos barcos de traineira que aportam na Ponta da Praia, em Santos, no caso da sardinha, e em Registro, diretamente das rêdes dos pescadores, no caso da manjuba.

A sardinha, adquirida no período da manhã, foi transportada de Santos para o laboratório de São Paulo numa caixa provida de 
2" de material isolante, sob refrigeração direta com gêlo britado, tendo sido salgada à tarde do mesmo dia.

A manjuba foi salgada na própria praia em que foi adquirida, dada a ausência de fábrica de gêlo em Registro.

$\mathrm{Na}$ tabela I apresentamos os dados referentes às amostras de sardinha.

TABELA I

Sardinha

\begin{tabular}{l|c|c|c|c|c|c}
\hline & & & Comprimen- & \multicolumn{2}{|c}{ Composiçâo quínica (\%) } \\
\cline { 4 - 6 } & Data & Pêso $(\mathrm{g})$ & $\begin{array}{c}\text { Cocal } \\
\text { to (cm) }\end{array}$ & Agua & Gordura & Proteína \\
\hline I. Buzios & $28 / 4$ & 44,7 & - & 70,31 & 9,14 & - \\
I. Grande & $10 / 5$ & 57,5 & 15,39 & 69,6 & 7,3 & 20,7 \\
I. Grande & $24 / 5$ & 55,0 & 15,7 & 70,2 & 9,45 & 20,86 \\
I. Grande & $31 / 5$ & 45,5 & 14,3 & 74,5 & 3,83 & 20,11 \\
I. Grande & $7 / 6$ & 55,5 & 15,44 & 73,82 & 4,45 & 20,95 \\
\hline
\end{tabular}

Nota - Local: o nome da ilha indica a vizinhança onde foi pescada a sardinha. Data: é a de aquisição no mercado de Santos. Pêso: é o pêso médio. Comprimento: comprimento padrão médio.

2) Métodos de salga. - Em linhas gerais, procuramos reproduzir o procedimento adotado nas indústrias, mas, no caso da sardinha, devido ao pequeno volume com que ensaiamos (cêrca de $1 \mathrm{~kg}$ por vez), procedemos da seguinte forma.

Conhecido o pêso da amostra de peixe, tomou-se o sal, do tipo fino comumente utilizado nas indústrias de salga, em quantidade correspondente a cêrca de $30 \%$ do pêso dos peixes. Forrou-se o fundo de um recipiente circular, de cêrca de $30 \mathrm{~cm}$ de diâmetro, com uma camada de ca. $0,5 \mathrm{~cm}$ de sal. Dispôs-se os peixes paralelamente entre si, com o dorso para baixo e ligeiramente deitados de lado, tendo a cabeça encostada na parede do recipiente, de modo que os exemplares se cruzem pela cauda. Essa disposição possibilita diminuir o montante do espaço vazio entre os exemplares. Cada exemplar foi, de antemão, mergulhado no sal para que o mesmo ficasse envolto por uma camada dêste último. Feita a camada de peixes, cobriu-se com outra de sal e, sôbre esta, fêz-se outro extrato de peixes. O sal que sobrou foi despejado sôbre a última camada, para que a mesma ficasse inteiramente encoberta. Por fim, colocou-se uma tábua e, sôbre esta, um pequeno pêso, o suficiente para manter os peixes submersos na salmoura que se formou. 
No caso da manjuba, a salga foi feita em barricas de madeira, de 10 litros de capacidade. Não nos preocupamos, desta vez, em dar disposição regular aos exemplares. Forrado o fundo do vasilhame com uma camada de sal, seguiam-se-lhe, alternadamente, as de peixe e as de sal.

3) Preparo do material e método de análise. - Adotamos o método oficial da A.O.A.C. ${ }^{2}$ para peixes e produtos marinhos, a fim de dosarmos o cloro em têrmos de cloreto de sódio.

Os exemplares destinados à análise foram retirados dos respectivos recipientes a partir das camadas superiores, a fim de não perturbar sensivelmente o equilíbrio entre os peixes e a salmoura que os circundava.

Da sardinha só tomamos o filé de carne, com pele, mas sem escama. Para cada análise utilizamos dois exemplares.

No caso da manjuba, as análises foram feitas para o peixe integral, tomando-se 5-6 exemplares por vez.

O teor de água foi determinado pela secagem em estufa a $105^{\circ} \mathrm{C}$. O de gordura, pelo extrator de Sohxlet.

\section{RESULTADOS E DISCUSSÃO}

Nas tabelas II e III apresentamos os resultados das análises.

\section{a) SARDINHA.}

Nas condições em que se fêz a salga, a concentração do cloreto de sódio na carne atinge o nível de $18 \%$, em relação ao pêso da carne, e $36 \%$, em relação ao seu conteúdo de água, que é da ordem de $49-51 \%$.

Pela tabela de solubilidade ${ }^{3}$, vemos que o cloreto de sódio é solúvel até $36 \mathrm{~g} / 100 \mathrm{~g}$ de água, a $20^{\circ} \mathrm{C}$, e até $36,3 \mathrm{~g} / 100 \mathrm{~g}$ de água, a $30^{\circ} \mathrm{C}$. Portanto, pela ordem de grandeza, a água da carne estaria saturada, mesmo na hipótese de estar tôda ela no estado livre, não combinada. Por outro lado, vamos encontrar na literatura os seguintes dados relativos a peixes salgados, não sêcos:

\begin{tabular}{|c|c|c|c|c|}
\hline & Espécie & $\mathrm{ClNa} \%$ & Referência & bibliográfica \\
\hline "Sardinella" & .. & 17,2 & & 4 \\
\hline "Sardinha" & $\ldots \ldots \ldots \ldots \ldots \ldots \ldots$ & 17,8 & & 5 \\
\hline "Arenque" & $\ldots \ldots \ldots \ldots \ldots \ldots \ldots$ & 18 & & 6 \\
\hline
\end{tabular}

Pelo exposto, podemos admitir que, em nosso caso, a carne de sardinha pode ser considerada como pràticamente saturada de cloreto de sódio em cêrca de 15 dias. 


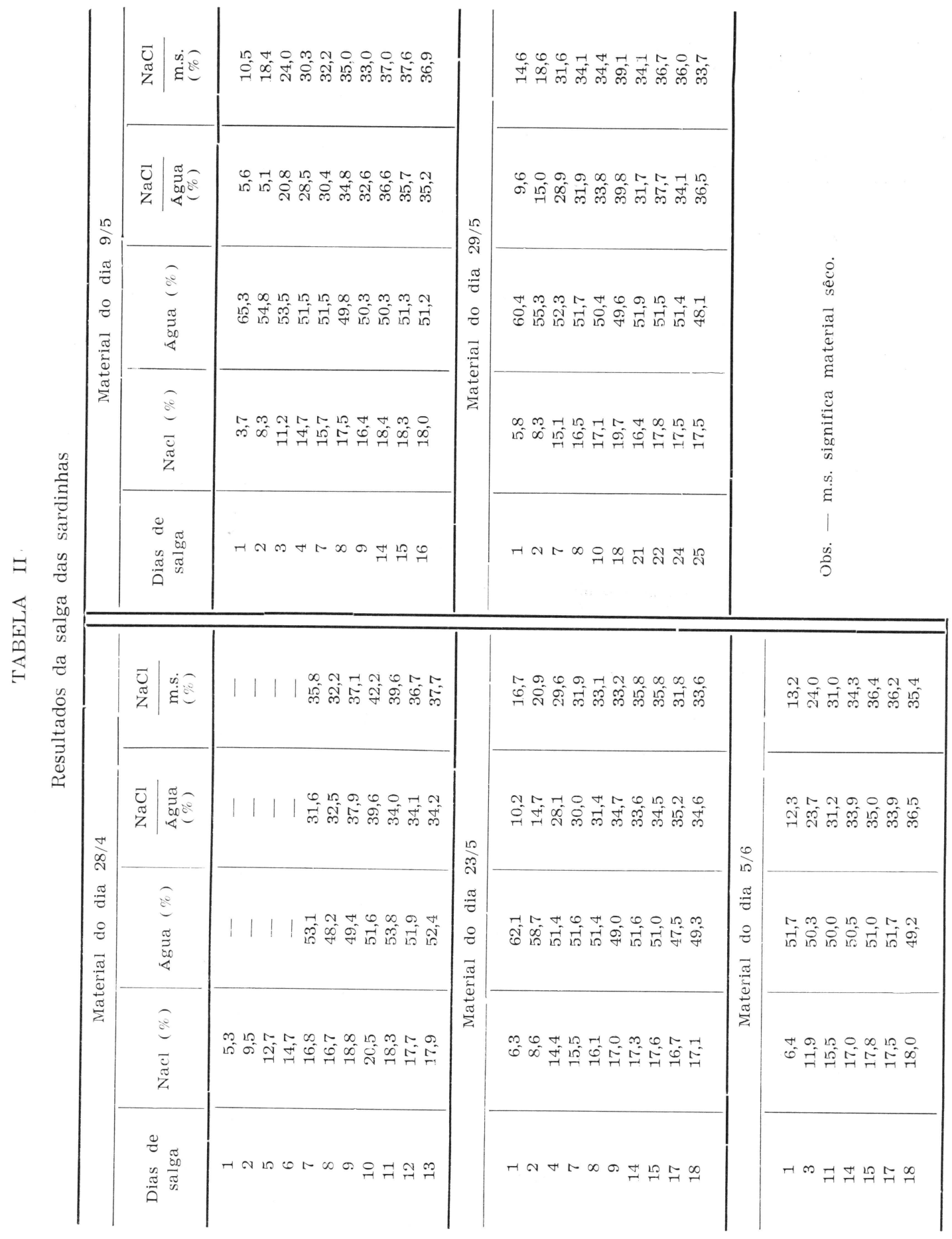




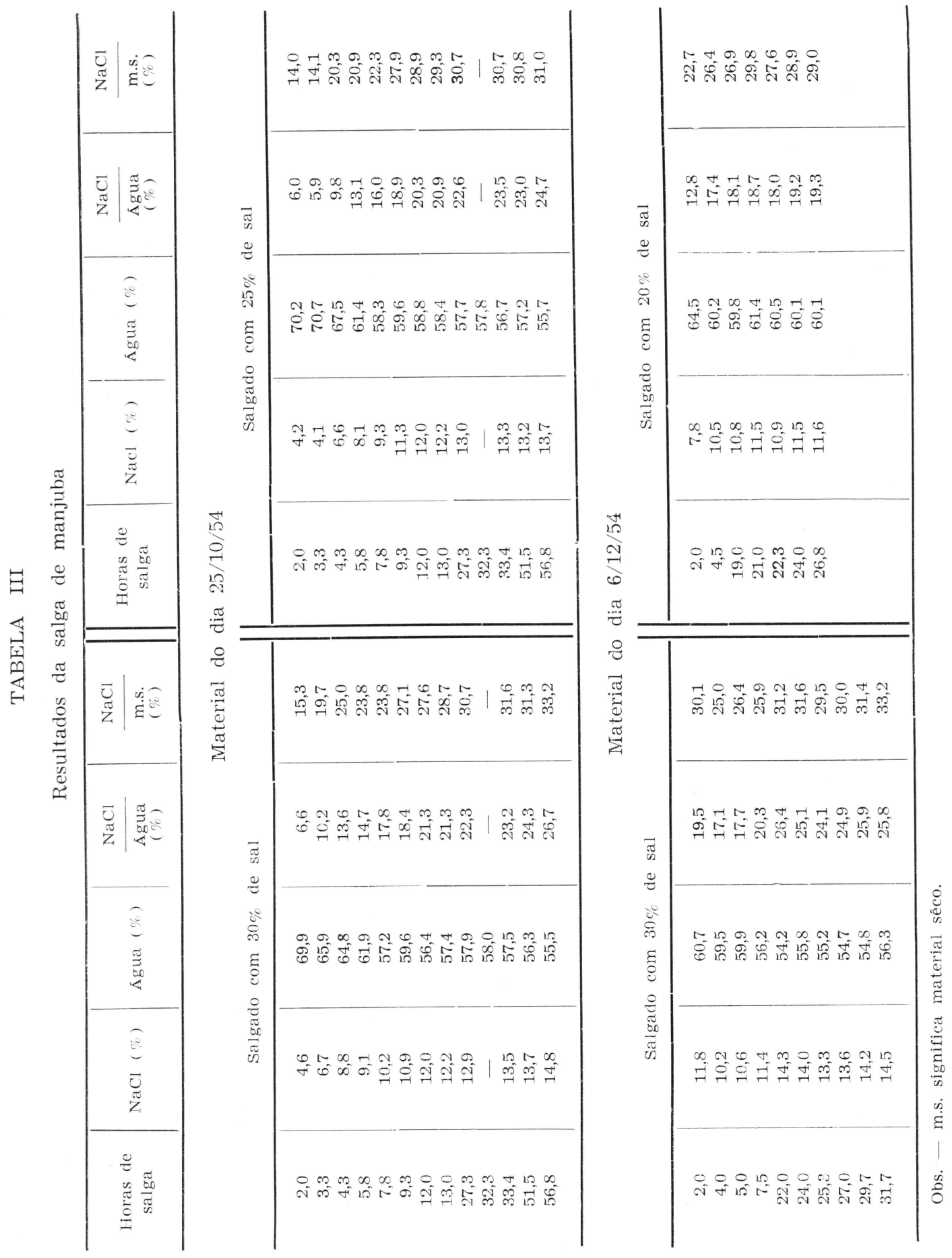


Os resultados mostram ainda que, passado êsse período inicial de saturação, a concentração do cloreto de sódio sofre pequeno decréscimo, tendo sido êsse fato observado nos cinco ensaios realizados. Êsse fenômeno já foi observado por Sasa $(1902,1903,1904)^{7}$ em relação à carne do arenque. Segundo êsse autor, os estados de saturação foram os seguintes, atribuindo-se o valor 100 à máxima concentração alcançada aos 7 dias de salga:

$\begin{array}{llrrrrr}\text { Dias } \ldots \ldots & 7 & 14 & 28 & 90 & 180 \\ \text { Concentração de } \text { sal } \ldots \ldots \ldots \ldots \ldots & 100 & 95 & 85 & 94 & 94\end{array}$

Para a sardinha, nas condições em que foi feita a salga, foram necessários cêrca de 15 dias para ser atingida a máxima concentração.

Em nossas indústrias, a sardinha é atirada ao tanque a granel e, nessas condições, pode-se admitir que o volume do vazio que fica entre os peixes é maior do que aquêle tolerado em nossos ensaios. Isso significa que, para a mesma proporção de sal em relação ao peixe, o contato dêste último com o primeiro vem a ser menos uniforme, menos perfeito, podendo-se, conseqüentemente, contar com o retardamento da penetração do sal na carne.

No mesmo sentido influi o teor de gordura, fato perfeitamente comprovado, sendo necessário tanto mais tempo quanto mais gorda fôr a carne. Nos resultados apresentados na tabela II não vemos, entretanto, influência marcante do teor de gordura, embora as amostras apresentem diferenças apreciáveis dêste último. Isso, entretanto, não será suficiente para desmentir a conclusão a que chegaram outros autores, visto que, os nossos ensaios não foram conduzidos sob condições perfeitamente controladas no sentido de comprovar o efeito em questão. Tendo-se em conta, porém, que duas das nossas amostras apresentam teor superior a $9 \%$, nível êsse dos mais elevados, segundo as análises feitas por nós em dois ciclos completos, devemos admitir que o período de saturação correspondente àquelas amostras deve ser tomado como o mínimo necessário para efeito de segurança.

Outro fator que influi sôbre a rapidez de saturação é o tamanho dos exemplares. Na tabela I fizemos constar os valores médios dos comprimentos "standard" dos exemplares (médias de 18-20 indivíduos). Comparando-os com aquêles encontrados por outros autores ${ }^{8,9}$, verifica-se que as nossas amostras são de tamanho médio, não podendo ser consideradas como das maiores, embora sejam oriundas da região da Ilha Grande, de onde procedem os maiores exemplares comumente encontrados na praça de São Paulo. 
Por essas considerações e à luz dos resultados obtidos, poderíamos dizer que as indústrias que não costumam manter os serviços de análise, devem conservar a sardinha em tanque por um período mínimo de ca. 15 dias para que o peixe fique pràticamente saturado de sal. A especificação mais precisa, entretanto, deverá ser estabelecida mediante a análise dos exemplares tomados in loco dos tanques das indústrias.

\section{b) Manjuba.}

O período de saturação, para a manjuba, é bem mais curto, o que é compreensível, dado o seu pequeno porte e a presença de pouca escama.

Pelos resultados apresentados na tabela III, observamos que,

1) Tanto para 20 como para $30 \%$ de sal em relação ao pêso do peixe, a saturação da carne tende ràpidamente para um limite, em cêrca de 24 horas de salga.

2) Ainda que se utilizasse $30 \%$, quantidade essa superior àquela habitualmente consumida pelas indústrias de salga do Vale do Rio Ribeira, que é da ordem de $3,5-4,0 \mathrm{~kg}$ por meio "alqueire" (correspondente a ca. $15 \mathrm{~kg}$ de peixe, ou seja, o pêso do peixe contido em uma lata de querosene de 20 litros), a concentração do cloreto de sódio na carne não ultrapassa de $14 \%$, sendo de apenas $11 \%$ no caso de $20 \%$ de sal. Em relação à água da carne, a concentração não atinge $26 \mathrm{~g} / 100 \mathrm{~g}$ de água. A relação $\mathrm{ClNa} /$ matéria sêca é, também, muito baixa, não tendo alcançado o nível de $34 \%$.

Êsses resultados estão muito aquém daqueles observados com a sardinha. Poderíamos, antes de tudo, atribuir essa deficiência ao fato de têrmos transportado as barricas de salga em caminhoneta, de Registro a São Paulo, durante o dia em que se fêz a salga. É possível que, por efeito da trepidação, os grãos de sal, inicialmente intercalados entre os peixes, tenham descido para o fundo do vasilhame, deixando os peixes em contato com a salmoura de concentração deficitária. Entretanto, se examinarmos os algarismos obtidos da manjuba salgada e sêca ao sol ou em estufa ${ }^{10}$, recebida das indústrias, vamos encontrar os seguintes resultados:

$$
\mathrm{NaCl}(\%) \quad \mathrm{NaCl} / \text { matéria sêca }(\%)
$$

$\begin{array}{ccc}\text { Teores extremos } \ldots \ldots \ldots & 11,99-21,67 & 22,10-33,10 \\ \text { Média de } 17 \text { amostras } \ldots & 16,85 & 27,62\end{array}$


Os nossos dados são, portanto, da mesma ordem de grandeza, ao cabo de 24 horas de salga. Isso significa que os nossos ensaios retratam aproximadamente o que realmente ocorre nas indústrias. Êsse período de 24 horas está perfeitamente de acôrdo com as informações obtidas pelo autor, em 1950, de uma dezena de estabelecimentos de salga do Vale do Rio da Ribeira, segundo as quais a permanência de pelo menos 24 horas em tanque seria obrigatória para a perfeita "cura" da manjuba.

Quanto ao teor de sal inferior a $15 \%$, que é baixo, se comparado com o de $18 \%$ da sardinha, o mesmo não representa o limite de saturação, pois vamos encontrar os seguintes resultados nas manjubas conservadas em salmoura por períodos mais longos:

\begin{tabular}{|c|c|c|c|c|}
\hline Salgado em & Analisado $\mathrm{em}$ & $\mathrm{NaCl}(\%)$ & Agua $(\%)$ & Material \\
\hline $26-10-54 \ldots \ldots$ & $26-11-54$ & 16,3 & - & Manjuba integral \\
\hline Safra de 1955- & & 18,46 & 55,0 & Filé de carne \\
\hline$\ldots \ldots \ldots$ & $2-9-58$ & 18,63 & 55,9 & Manjuba integra! \\
\hline
\end{tabular}

A carne da manjuba pode, pois, incorporar tanto sal quanto a da sardinha. O fato de não conseguirmos alcançar teor superior a $15 \%$ em 24 horas de salga pode ser atribuído à insuficiência da quantidade de sal utilizado na salga e, também, à má distribuição do sal por entre os exemplares. Qualquer que seja o fator responsável, não haverá necessidade de nos preocuparmos em elevar o grau de saturação, desde que as indústrias continuem com a operação complementar de secagem em estufa. Se, contudo, resolverem lançar ao mercado produtos salgados não secos, torna-se recomendável procederem à "cura" mais perfeita. Desde que perfeitamente saturada de sal e mantida submersa na salmoura concentrada, a manjuba pode ser conservada por longo tempo, o que foi verificado com um lote da safra de 1955/56, que se apresenta em perfeito estado até o presente (mais de um ano e meio de conservação em salmoura). O seu conteúdo de sal consta da tabela acima.

\section{R ES U M O}

1) A sardinha verdadeira (Sardinella aurita, Rafinesque), quando salgada sem ser aberta, com cêrca de $30 \%$ de sal em relação ao seu pêso, pode incorporar ca. $18 \%$ de $\mathrm{NaCl}$, em relação ao seu pêso depois de salgada, e êsse teor pode ser alcançado em ca. 15 dias de salga. Êsse período de salga deve ser considerado como o mínimo necessário para efeito de segurança, tendo em vista a variação do tamanho, do teor de gordura e a imperfeição na distribuição do sal. 
2) Quanto à manjuba (Anchoviella hubbsi, Hildebrand), cuja produção è quase totalmente destinada à salga e secagem, a penetração do sal se processa ràpidamente em 24 horas de salga, sendo atingido o teor de $14-15 \%$ de $\mathrm{NaCl}$. A concentração máxima de $\mathrm{NaCl}$ que pode ser incorporado à carne é da ordem de $18 \%$, tendo sido observado êsse teor num lote conservado na salmoura por um período superior a um ano e em perfeito estado de conservação.

\section{AGRADECIMENTOS}

Agradeço sensibilizado ao Sr. João de Paiva Carvalho pela sua habitual solicitude com que nos tem atendido para melhorar a redação e a apresentação dêste trabalho.

Devo, ainda, assinalar que os dados experimentais foram na maioria obtidos pela participação ativa dos Srs. Miguel Cuocolo e Clarimundo de Jesus nos trabalhos de laboratório, aos quais deixo consignados os meus agradecimentos.

\section{S U M M A R Y}

Sardine (Sardinella aurita, Rafinesque) and Manjuba (Anchoviella hub$b s i$, Hildebrand) are the two species of fish most commonly salted at the coast of São Paulo. As there exists a general incertainity about the curing time, it was found interesting to carry out some experiments in order to clarify this question. The present paper gives an account for the work and the results obtained up to now in the Technical Laboratory of the Institute.

1. When Sardine is salted round with about $30 \%$ salt calculated on the fresh fish weight, may incorporate about $18 \% \mathrm{NaCl}$ on the salted fish weight basis. This salt content is reached practically in about 15 days. Considering the variability of thickness and fat content of the fish and the unequal distribution of salt, which may occur in the industrial procedure of salting, the curing period of about 15 days must be taken as the minimum necessary to ensure a perfect cure. The table II shows the rate of salt penetration, salt-water ratio and salt-dry material ratio.

2. In the case of manjuba, whose production is almost entirely destinated to salting and drying, the salt penetration proceeds rapidly during the first day, when the salt content stabilizes at the level of about $14-15 \%$. The maximum concentration eventually attainable is about $18 \%$, if the fish is maintained in saturated brine for a long time. Provided that the manjuba is kept in saturated brine and properly cured, it may be preserved in good conditions for more than one year. The table III gives the rate of salt penetration observed in manjuba salted with 30,25 and $20 \%$ of salt on fresh fish weight basis.

\section{B I B L I O G R A F I A}

1. TANIKaWa, E.

1949. Produtos alimentícios salgados. $6^{n}$ edição. p. 37-49. Em japonês.

2. Association of Official Agricultural Chemists.

1950. Methods of analysis. $7^{\text {a }}$ edição. p. 296-297. 
3. LANGe, N. D.

1949. Handbook of Chemistry. $7^{*}$ edição. p. 1258-1259.

4. Krishnapillai, V. et al.

1956. Indian Jour. of Fisheries, tomo 3, n. ${ }^{\circ} 1$, p. 43. (in Extr. de la Pesca Mundial, FAO, nov.-dez., 1957, p. 31).

5. Velanker, N. K.

1952. Journal of Scientific and Industrial Research, tomo $2 \mathrm{~A}, \mathrm{n}^{\circ} \mathrm{8}$, p. 359, Nueva Delhi, India. (in Extr. de la Pesca Mundial, FAO, jul-ago., 1953, p. 25).

6. EMPEY, W. A.

1952. Fisheries Newsletter, tomo 11, n. ${ }^{\circ}$ 11, p. 9, Austrália. (in Extr. de la Pesca Mundial, FAO, mai.-abr., 1953, p. 31).

7. SASA,

1902/04. Rept. of Hokkaido Fishery Institute. (in Produtos alimenticios salgados, Tanikawa, E., 1949). Em japonês.

8. TOMMASI, L. R.

1958. Dados não publicados, fornecidos por J. de Paiva Carvalho, Seção de Oceanografia Biológica do Instituto Oceanográfico.

9. Gonçalves, A.

1954. Dados não publicados. Medições feitas por Clarimundo de Jesus, por ordem do autor.

10. Teixeira e Silva, H. M.

Dados não publicados das análises feitas na Seção de Industrialização e Conservação do Departamento da Produção Animal, Secretaria da Agricultura do Estado de São Paulo. 